\title{
ERRATUM
}

\section{Erratum to: Albumin administration in the acutely ill: what is new and where next?}

\author{
Jean-Louis Vincent ${ }^{1 *}$, James A Russell ${ }^{2}$, Matthias Jacob ${ }^{3}$, Greg Martin ${ }^{4}$, Bertrand Guidet ${ }^{5,6}$, Jan Wernerman ${ }^{7}$, \\ Ricard Ferrer ${ }^{8}$, Stuart A McCluskey ${ }^{9}$ and Luciano Gattinoni ${ }^{10}$ \\ See related review by Vincent et al., http://ccforum.com/content/18/4/231
}

\section{Erratum}

After publication of this review [1], we noticed that the author name Ricard Ferrer Roca should instead be stated as Ricard Ferrer.

\begin{abstract}
Author details
'Department of Intensive Care, Erasme Hospital, Université libre de Bruxelles, route de Lennik 808, 1070 Brussels, Belgium. ${ }^{2}$ Center for Heart Lung Innovation and Critical Care Medicine, University of British Columbia and St. Paul's Hospital, Vancouver V6Z BC, Canada. ${ }^{3}$ Department of Anaesthesiology, University Hospital Munich, Nussbaumstraße 20, 80336 Munich, Germany. ${ }^{4}$ Department of Medicine, Division of Pulmonary, Allergy and Critical Care, Emory University School of Medicine, Atlanta, GA 30303, USA. ${ }^{5}$ Service Réanimation Médicale, Hôpital Saint Antoine, Universitaires Est Parisien, Paris, France. ${ }^{6}$ Sorbonne Universités, UPMC Université Paris 06, UMR-S 1136, Institut Pierre Louis d'Epidémiologie et de Santé Publique, Paris F-75013, France. ${ }^{7}$ Department of Anesthesiology \& Intensive Care Medicine, Karolinska University Hospital, Huddinge, 14186 Stockholm, Sweden. ${ }^{8}$ Servei de Medicina Intensiva, Hospital Universitari Mútua Terrassa, Universitat de Barcelona, CIBER Enfermedades Respiratorias, Terrassa, 08221 Barcelona, Spain. ${ }^{9}$ Department of Anesthesia and Pain Management, Toronto General Hospital, University of Toronto, Toronto, ON M5G 2C4, Canada.

${ }^{10}$ Dipartimento di Anestesia, Rianimazione (Intensiva e Subintensiva) e Terapia del Dolore, Fondazione IRCCS Ca' Granda - Ospedale Maggiore Policlinico, Milan 20122, Italy.
\end{abstract}

Published online: 19 November 2014

\section{Reference}

1. Vincent JL, Russell JA, Jacob M, Martin G, Guidet B, Wernerman J, Ferrer R, McCluskey SA, Gattinoni L: Albumin administration in the acutely ill: what is new and where next? Crit Care 2014, 18:231.

\footnotetext{
* Correspondence: jlvincen@ulb.ac.be

'Department of Intensive Care, Erasme Hospital, Université libre de Bruxelles, route de Lennik 808, 1070 Brussels, Belgium

Full list of author information is available at the end of the article
} 